\section{Diversidade da pesquisa em história das ciências no Brasil}

\author{
Por Anna Raquel de Matos Castro \\ Museu Paraense Emílio Goeldi \\ (annaraquelcastro@yahoo.com.br)
}

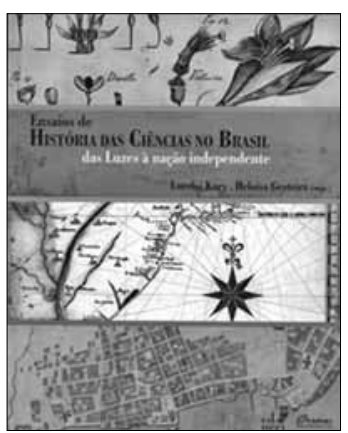

KURY, Lorelai; GESTEIRA, Heloisa (Orgs.). Ensaios de história das ciências no Brasil: das Luzes à nação independente. Rio de Janeiro: EDUERJ, 2012. 328 p. il. ISBN 978-85-7511-239-7

O livro organizado por Lorelai Kury e Heloisa Gesteira se propõe a realizar uma análise histórica em torno da institucionalização dos estudos científicos no Brasil, com ênfase no período entre a era Pombalina e a Independência, passando pela transferência da Corte portuguesa para o Brasil. Dividido em cinco partes e reunindo artigos de pesquisadores de diferentes campos e especialidades, o livro destaca as mudanças políticas, econômicas, sociais e geográficas que contribuíram para o início das atividades técnicas e científicas no Brasil.

Os trabalhos que compõem o livro desmistificam a ideia de que a institucionalização das ciências no Brasil se deu somente a partir da instauração das universidades, já no século $X X$. Como enfatizam as organizadoras na apresentação desta obra, tal pensamento, predominante na historiografia da década de 1980, "impunha um limite cronológico estreito para as pesquisas em história das ciências", além de ser uma perspectiva que acabava por colocar em um patamar de atraso as "práticas científicas realizadas no Brasil - sobretudo na época colonial quando comparadas com os estágios de desenvolvimento científico e tecnológico dos países considerados centrais no sistema internacional". primeiro capítulo é um dos que remete à desconstrução deste pressuposto. Eliane Fleck nos mostra o quanto o conhecimento indígena sobre as plantas medicinais contribuiu para as práticas curativas desenvolvidas pelos missionários jesuítas na província do Paraguai e para a formação de farmacopeias desde o século XVI, quando a medicina ainda não era um saber especializado, estendendo-se pelos séculos XVII e XVIII, com o surgimento das Cartas Ânuas. Neste sentido, atesta-se a racionalização cada vez maior dos elementos da natureza. Como afirma Fleck, "experimentalismo e pensamento racional parecem ter convivido harmoniosamente com as práticas ocidentais tradicionais e as percepções mágicoritualísticas nas reduções jesuíticas" (p. 24). Tem-se, então, uma medicina que mesclava conhecimentos europeus e nativos na busca pela cura de enfermidades.

Ainda sobre as artes de curar, Márcia Ribeiro, Betânia Figueiredo e Graciela Oliver trazem à tona estudos sobre o conhecimento desenvolvido a partir da transferência da Corte portuguesa para o Brasil. As pesquisas retratam as significativas mudanças na ciência brasileira com a chegada da Família Real, oportunizando um maior intercâmbio científico com o mundo europeu e mudando o cenário cultural de outrora. Figueiredo e Oliver chamam a atenção para a expansão urbana do Rio de Janeiro, objetivando um ambiente considerado mais saudável para os habitantes. As modificações urbanas relacionavam-se a fatores como "o aumento de números de médicos formados nos espaços acadêmicos, a circulação de novas ideias no mundo da cura e o aumento expressivo de europeus circulando no Brasil" (p. 41). Ribeiro, por sua vez, destaca as transformações no pensamento médico, especialmente a partir da criação de instituições de ensino - como as escolas médicocirúrgicas, mais tarde transformadas em faculdades - e da promulgação de legislação voltada para o campo da medicina. O pensamento médico de início do século XIX expandia-se "rumo ao pensamento europeu, ficando para trás os principais modelos teóricos e práticos que haviam guiado a medicina até então" (p. 31), embora não houvesse

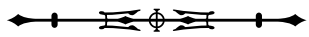


ocorrido um rompimento total com a antiga prática médica colonial. As publicações que tratavam das especificidades de determinadas doenças passaram a circular juntamente com livros escritos por homens de maior erudição, que tinham como foco a saúde coletiva, a cidade e seus habitantes. Desta forma, as atenções voltaram-se para a saúde pública e para a prevenção de enfermidades, fatores que estavam ligados às modificações do espaço urbano.

O Rio de Janeiro torna-se, então, o novo centro de conhecimentos médicos do governo português, na medida em que um número crescente de profissionais passa a circular no Brasil, coincidindo com uma maior organização do ensino institucionalizado e contribuindo para o surgimento, mais tarde, de faculdades de medicina. Neste contexto, Tânia Salgado Pimenta mostra a importância da Fisicatura-mor no processo de regulamentação das artes de curar durante parte do século XIX. Recriada em 1808, a Fisicatura-mor tinha por objetivo "controlar as artes de curar na metrópole e nas colônias (...)” (p. 54). Esse trabalho consistia na oficialização das práticas de cura que não eram adquiridas academicamente e tinha grande importância devido ao poder de atribuir legitimidade ao saber popular, permitindo a inclusão de seus praticantes entre as pessoas autorizadas ao exercício de algumas atividades médicas. No entanto, segundo a autora, muitos dos 'terapeutas populares' não procuraram a Fisicatura-mor nem foram procurados por ela para a regulamentação de suas práticas, sendo o órgão ignorado e considerado desnecessário por estes indivíduos.

Outro aspecto que merece atenção no livro são os estudos sobre a institucionalização das ciências a partir da observação da paisagem natural e urbana do Rio de Janeiro durante o período Joanino. Naturalistas viajantes deslumbravam-se com a exuberância da natureza tropical, e os diversos profissionais (engenheiros, desenhistas, arquitetos etc.) que passaram a circular pelo país planejaram ambientes considerados saudáveis de acordo com o discurso médico, tentando aliar os 'bons ares' que a natureza proporcionava à expansão urbana.
Considerando estes aspectos, Ana Rosa de Oliveira destaca a criação do Jardim Botânico como integrante da paisagem do Rio de Janeiro, o qual acabou por desempenhar os papéis de espaço público e instituição para a prática da ciência. Já o trabalho de Lorelai Kury destaca a 'necessidade' de modernização urbana a partir da alteração da paisagem, para atender as exigências de um espaço salubre para a população, de acordo com as crenças e práticas científicas do período. Gradativamente, a cidade sofreu "mudanças, aumentos e melhoramentos" (p. 92), transformando o espaço "entre o mar e o mangue" em um cenário heterogêneo e variado.

$O$ período anterior à chegada da Família Real também é investigado como um momento importante para o desenvolvimento das ciências naturais. As expedições científicas ocorridas durante o Iluminismo visavam à produção de conhecimento a partir do estudo sistemático da natureza. Como relatam Magnus Pereira e Ana Lúcia da Cruz, "o governo português procurou colocar a ciência a serviço do reconhecimento das potencialidades econômicas de seus territórios coloniais", o que justificava os investimentos nas expedições exploratórias ou viagens filosóficas durante o século XVIII (p. 115). Uma série de regras foi elaborada para a orientação dos viajantes no que concerne ao modo de observar, identificar, coletar e remeter para a metrópole amostras dos recursos naturais por eles encontrados. Conforme Pereira e Cruz, tais regras culminavam em inventários, que acabaram por desempenhar o papel de instrumentos de produção de conhecimento. Segundo os autores, os manuais de instrução para viagens científicas, produzidos em Portugal naquele século, caracterizavam-se pela pretensão enciclopedista predominante no ideário Iluminista.

Os recursos naturais que despertavam curiosidade tornaram-se objetos de estudo, de troca e de intercâmbio de informações entre naturalistas e instituições de várias partes do mundo, sobretudo as pertencentes à Europa das Luzes. Segundo João Carlos Brigola, isto fazia com que a natureza do império português e o desconhecimento em 
torno dela gerassem uma "expectativa internacional face à criação e à condução dos estabelecimentos museológicos lusitanos" (p. 135). Em seu trabalho, Brigola analisa o colecionismo científico português, tanto na metrópole como na colônia brasileira, em fins do Antigo Regime.

A obtenção de produtos de caráter utilitário, retirados do meio natural, também mereceu espaço no livro, particularmente no capítulo de Márcia Helena Ferraz, o qual retrata o contexto que envolveu o processo de fabricação da pólvora a partir da extração de salitre no final do século XVIII e início do XIX. A necessidade de matériaprima para a fabricação do produto foi alvo de diversas medidas por parte do governo português, na tentativa de obter pólvora para a defesa do território.

O livro não se furta a destacar trabalhos que relatam a contribuição de personagens importantes no processo de institucionalização das ciências no Brasil, a exemplo de Hipólito da Costa, José Mariano da Conceição Veloso e Martim Francisco Ribeiro de Andrada, sujeitos estudados por Neil Safier e Alex Varela. Safier analisa as viagens científicas e os trabalhos realizados por Hipólito da Costa e frei Conceição Veloso, para além das demarcações do império português. Por sua vez, Varela destaca o papel de Andrada enquanto naturalista, inicialmente tentando desvincular a imagem do homem público - já que Andrada foi o primeiro ministro da Fazenda do Brasil - comumente a ele associada na historiografia. Segundo reconhece Varela, "em sua trajetória histórica [de Andrada], a face de naturalista e os interesses políticos são indissociáveis" (p. 181).

Os debates em torno da relação entre ciência e construção do território brasileiro são evidenciados na quarta parte do livro, cujos textos abordam os conhecimentos técnico-científicos e suas contribuições para a transformação do espaço. Sobre esta questão, Beatriz Bueno trabalha com a formação do Estado Moderno a partir de "um território capaz de se constituir em 'objeto' de uma só legislação, de uma só fiscalidade e de uma só justiça" (p. 195). Para tanto, a autora analisa os investimentos na criação de instituições como o Arquivo Real Militar, a
Academia Real Militar, a Intendência Geral de Polícia e a Escola Real de Ciências, Artes e Ofícios.

A pesquisa de Nelson Sanjad aborda o Estado do GrãoPará e Rio Negro, analisando o processo de desconstrução política ocorrido naquela região com a transferência da Corte para o Rio de Janeiro. Sendo a maior unidade administrativa colonial portuguesa, até o início do século XIX, o Grão-Pará e Rio Negro foi beneficiado com investimentos da Coroa em razão da expansão imperial lusitana, sobretudo no comércio, na agricultura, na navegação e na urbanização, cujo processo requereu práticas e conhecimentos científicos. No entanto, mudanças conjunturais ocasionaram perdas significativas para a região, que se agravaram com a centralização política da Corte no Rio de Janeiro. Nesse período, segundo Sanjad, o processo de "construção de uma 'metrópole colonial' [Belém], fruto de investimentos regulares da Coroa e no qual a ciência e a tecnologia foram elementos importantes, começa a se fragmentar (...)" (p. 233). Por sua vez, o capítulo de Íris Kantor chama a atenção para a importância dos trabalhos técnicos de reordenamento territorial. Kantor destaca o papel da cartografia neste processo, sobretudo das instituições militares como locais de ensino e produção cartográficos, idealizando "um novo modo de conceber, projetar e gerir os domínios americanos” (p. 239).

Mudando o foco de análise, Ângela Domingues analisa as impressões da imperatriz Maria Leopoldina sobre - Brasil, a partir de cartas escritas nos primeiros anos de sua estada no Rio de Janeiro. Domingues chama a atenção para a variedade de interesses da imperatriz - culturais, científicos e mesmo políticos -, que traça comparações dos aspectos observados com o mundo europeu. Segundo a autora, embora as cartas de Leopoldina não possam ser identificadas como literatura de viagem, podem "contribuir para a melhor compreensão da 'imagem científica' do Brasil na Europa de sua época” (p. 262).

Na última parte do livro, encontram-se textos que retratam o período da llustração portuguesa e as trocas científicas e culturais ocorridas naquele contexto, assim como os seus reflexos no Brasil, sobretudo a partir de 
1808. Maria de Fátima Nunes analisa a importância do intercâmbio de instrumentos científicos entre Europa e Brasil para a construção de saberes especializados. Já Guilherme Neves discute o papel do conhecimento, sobretudo aquele que chama de "forçosamente escrito, de preferência impresso" (p. 281), no mundo luso-brasileiro do início do século XIX. Para Neves, as obras surgidas no período deveriam ter servido como instrumentos para o conhecimento da natureza, mas acabaram por limitar esse objetivo. Segundo o autor, no império português "as Luzes ficaram sufocadas por certas tradições sociais e culturais, impedindo que adquirissem aquele aspecto de 'uso público da razão' (...)" (p. 281). Por sua vez, Maria Rachel da Fonseca analisa o papel das instituições no período Joanino, as quais seriam um reflexo da diversidade de áreas que despertavam interesse, a exemplo da botânica, agricultura, mineralogia, química, matemática etc. Neste sentido, Fonseca ressalta a importância dos espaços institucionais como "instâncias de realização e divulgação de atividades científicas" (p. 304). Por fim, José Augusto Alves aborda o processo de modernização da imprensa a partir da criação do jornal "Correio Braziliense", que desempenhou um importante papel na difusão de assuntos relacionados à política, sociedade e cultura no período.

O livro organizado por Kury e Gesteira nos permite uma visão mais abrangente do processo de institucionalização das ciências no Brasil. Embora a maioria dos textos concentre a análise no Rio de Janeiro, sede da Corte, a coletânea desperta interesse sobretudo por apresentar de forma variada o intercâmbio entre Brasil e Portugal, bem como seus reflexos na construção de uma 'tradição' científica brasileira. 